\title{
Epigenetic Targets in the Diagnosis and Treatment of Prostate Cancer
}

\author{
Murugesan Manoharan, Kavitha Ramachandran, Mark S. Soloway, Rakesh Singal
}

Department of Urology (MM, MSS) and Sylvester Comprehensive and Cancer Center (MM, KR, RS, MSS) Miller School of Medicine, University of Miami, Miami, Florida, USA, and Miami VA Medical Center (RS), Miami, Florida, USA

\begin{abstract}
Prostate cancer (PC) is one of leading cause of cancer related deaths in men. Various aspects of cancer epigenetics are rapidly evolving and the role of 2 major epigenetic changes including DNA methylation and histone modifications in prostate cancer is being studied widely. The epigenetic changes are early event in the cancer development and are reversible. Novel epigenetic markers are being studied, which have the potential as sensitive diagnostic and prognostic marker. Variety of drugs targeting epigenetic changes are being studied, which can be effective individually or in combination with other conventional drugs in PC treatment. In this review, we discuss epigenetic changes associated with PC and their potential diagnostic and therapeutic applications including future areas of research.
\end{abstract}

Key words: prostate cancer; DNA methylation; epigenesis, genetic

Int Braz, J Urol. 2007; 33: $11-8$

\section{INTRODUCTION}

Prostate cancer (PC) is one of leading cause of cancer related deaths in men. In the United States, an estimated 230,000 men were diagnosed with PC in the year 2005 and approximately 30,000 are expected to die from this cancer annually (1). Epigenetics refers to stable non inherited changes in the gene expression without alterations in DNA structure (2).

With the advent of prostate specific antigen (PSA) in 1998, there has been dramatic increase in the diagnosis of PC (3). The American Cancer Society recommends annual screening of men above the age of 50 for PC with PSA and rectal examination (4). However, it is not clear whether the PSA is effective in the diagnosis of PC as it lacks both specificity and sensitivity $(5,6)$. About $25 \%$ men with normal PSA may harbor PC (5) and PSA less than $20 \mathrm{ng} / \mathrm{mL}$ may not differentiate between PC and benign conditions (6). This leads to unnecessary prostate biopsies and on the other hand, we might miss PC in patients with low PSA. Similarly, there is lack of effective prognostic markers to predict the behavior of $\mathrm{PC}$ and outcome following definitive treatment. Novel biomarkers based on epigenetic profiling are being explored to aid in the diagnosis and management of PC (7-9).

Epigenetics is one of the rapidly expanding fields in cancer related research. Recent studies have shown that epigenetics plays an important role in cancer biology, somatic gene therapy, viral infections, genomic imprinting. Epigenetic changes, particularly the DNA methylation is found to be involved in a 
variety of cancers including colon, lung, breast and ovarian cancers apart from prostate cancer (8). Unlike passively transferred genetic mutations, the epigenetic changes must be actively maintained and its "reversibility" makes them a potential therapeutic target (10).

In this review, we discuss epigenetic changes associated with prostate cancer and their potential diagnostic and therapeutic applications including future areas of research.

\section{BASICS OF EPIGENETICS}

\section{Genome}

Approximately 23,000 genes are contained in the human genome. For proper functioning of the cells, these genes should be expressed in specific cells at specific times (11). The chromatin is a nucleoprotein complex made of nucleosomes. The nucleosomes are made of DNA, which are wrapped around octamers of globular histone proteins (12). The changes in the chromatin structure influence the gene expression. When the chromatin is condensed, the gene expression is "switched off" and when it is open, the gene expression is "switched on" (13). The status of chromatin is dynamic and can be controlled by reversible epigenetic mechanisms.

The two important, well studied epigenetic mechanisms are DNA methylation and histone modifications such as acetylation. These two processes can act independently and/ or together affecting the gene expression and in turn the tumorigenesis.

\section{DNA Methylation in Prostate Cancer}

DNA methylation refers to a covalent chemical modification, resulting in the addition of a methyl ( $\mathrm{CH} 3)$ group at the $\mathrm{C}-5$ position of the Cytosine ring in the DNA. The human genome is not uniformly methylated. "CpG islands" are small regions within the genome that are rich in Cytosine and Guanine bases and are mostly unmethylated (8). Epigenetic alterations target this region thereby affecting gene expression. Both the hyper and hypomethylation can affect the gene expression and the role of DNA methylation in oncogenesis has been studied for several years.

\section{DNA Hypermethylation}

DNA hypermethylation is a well established epigenetic abnormality seen in several malignancies, more importantly in prostate cancer (9). Carcinogenesis is a multi step process and hypermethylation is hypothesized as an early event in the development and progression of prostate cancer (14). Hypermethylation of the gene is facilitated by a group of enzymes known as DNA methyltransferases (DNMT), which includes DNMT1, DNMT1b, DNMT1o, DNMT1p, DNMT2, DNMT3a, DNMT3b and DNMT3L (15). The hypermethylation involves the $\mathrm{CpG}$ islands in the promoter regions that results in the silencing of the genes that are involved in tumor suppressor activity, DNA repair and other critical cellular mechanisms.

Some of the important genes that are frequently hypermethylated in prostate cancer are listed in Table1. Glutathione S-transferase P1 (GSTP1) is a protector gene and silencing this gene by hypermethylation leads to DNA damage and cancer initiation $(7,16)$. Methyl Guanine DNA methyl transferase (MGMT) is another DNA repair gene which are silenced by hypermethylation (17). Inactivation of putative tumor suppressor genes by hypermethylation, such as Ras association domain family 1 gene (RASSF1A) $(18,19)$, KAI 1 (20), Inhibin-alpha (21) and DAB21P (22). Hypermethylation promotes carcinogenesis in prostate cancer by affecting cell cycle control, hormonal response, cell adhesions and architecture (14).

Table 1 - Hypermethylated genes in prostate cancer.

\begin{tabular}{ll}
\hline Gene & \multicolumn{1}{c}{ Mechanism } \\
\hline GSTP1 & DNA repair \\
RARB & Hormone response \\
CD44 & Tumor invasion \\
RASSF1 & Signal transduction \\
MGMT & DNA repair \\
AR & Hormone response \\
ESR1,2 & Hormone response \\
APC & Tumor invasion \\
DAB21P & Signal transduction \\
\hline
\end{tabular}




\section{DNA Hypomethylation}

DNA hypomethylation is a second type of methylation related epigenetic aberration seen in variety of malignancies including prostate cancer (23). Hypomethylation is facilitated by enzyme group demethylases which includes 5-methylcytosine glycosylase and MBD2b (24). Methylation of normal genomes act as defensive mechanisms against cancer, for example, the oncogenes can be transcriptionally silenced and prevented from propogating by being methylated. The hypomethylation causes breakdown of this defense mechanism and is implicated in the tumor genesis.

The hypomethylation can be "global" or "localized". Global hypomethylation refers to overall decrease in methylation content in the genome. Bedford et al. reported that global hypomethylation is significantly lower in patients with metastatic prostate cancer compared to non metastatic prostate cancer (23). Localized or gene specific hypomethylation refers to a decrease in cytosine methylation relative to normal levels. This affects the specific regions within genome such as promoter regions of oncogenes which are highly methylated (9).

\section{Histone Code}

Histones have emerged as important regulators of chromatin, thereby controlling gene expression. In each nucleosome, two super helical turns of DNA containing around 146 base pairs wrap an octomer of histone core made of four histone partners (an $\mathrm{H} 3-\mathrm{H} 4$ tetramer and two $\mathrm{H} 2 \mathrm{~A}-\mathrm{H} 2 \mathrm{~B}$ diamers (25). Histones consist of a globular domain and a more flexible and charged $\mathrm{NH} 2$ terminal called as histone "tail". These tails which are placed peripherally are susceptible for a variety of covalent modifications, such as acetylation, methylation, phosphorylation and ubiquitination. These modifications are referred as "the histone code" and is effective epigenetic mechanism regulating gene expression (26).

Histone acetylation and deacetylations are mediated by histone acetyl transferases (HAT) and histone deacetylases (HDAC) respectively. Huang et al. and Tsubaki et al. reported that treatment of prostate cancer cells with HDAC inhibitors results in increased expression of specific genes such as CPA3 (27) and Insulin like growth factor binding protein 3 (28). Coxsackie and adenovirus receptor (CAR) gene and Vitamin D receptor gene have been shown to be affected by histone acetylation in prostate cancer. Decreased CAR expression is associated with an increased Gleason score (29).

Histone methylation affects the chromatin function depending on the specific amino acid being modified and the extent of methylation (30). Methylation of $\mathrm{H} 3$ at lysine 4 is associated with inactive transcription of the PSA gene in prostate cancer cell line LNCaP and decreased di and trimethylated $\mathrm{H} 3$ at lysine 4 is associated with $\mathrm{AR}$ mediated transcription of the PSA gene (9). No histone demethylases have been described so far and it is postulated that histone methylation may be relatively stable and even irreversible (30).

\section{DNA Methylation - Histone Code Interplay}

DNA promoter methylation and histone deacetylation can act synergistically resulting in inactive chromatin state resulting in suppression of gene expression (Figure-1). Methylated DNA binding proteins such as $\mathrm{MeCP} 2$ may play an important role. Retinoic acid receptor beta gene (RARB) which is silenced in prostate cancer tissues and cell lines is regulated by both methylation and histone acetylation. This indicates that combined treatment targeting methylation and histone acetylation may result in reversal of epigenetic silencing of tumor suppressor genes $(9,31)$. Similarly, DNA methylation and histone methylation may interact to facilitate chromatin silencing. However, it is unclear which event takes place first (9).

\section{Epigenetic Diagnostic Markers}

Prostate specific antigen (PSA) is a less than optimal tumor marker and cannot effectively differentiate between prostate cancer and other conditions such as prostatitis, benign prostatic hyperplasia. The false positive results lead to expensive and invasive investigations such as transrectal prostate biopsy. This provides the opportunity to the researchers to identify potential epigenetic markers in the diagnosis of prostate cancer. 

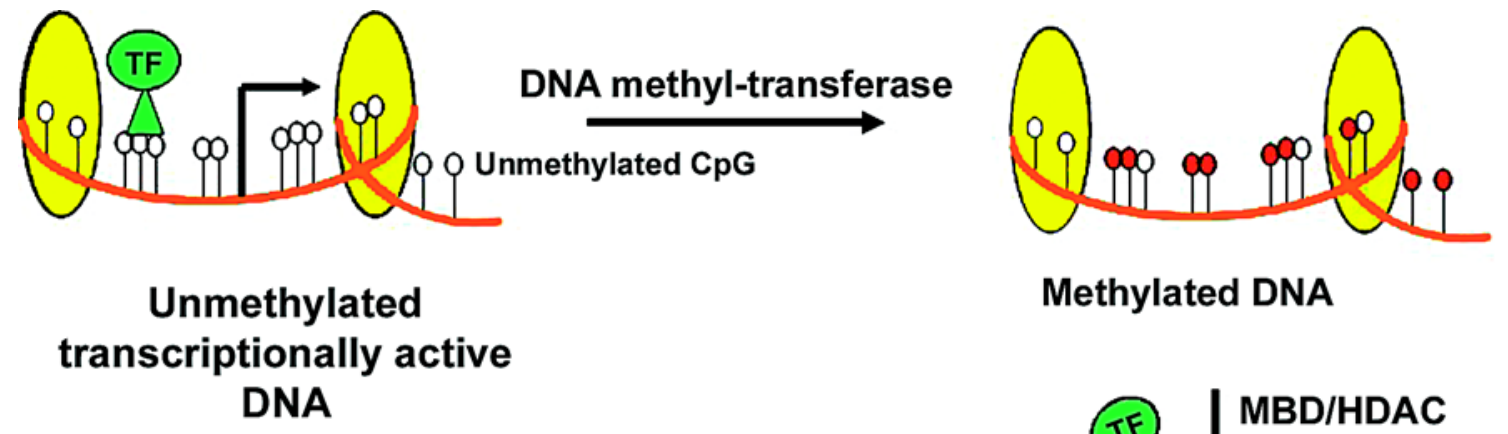

Methylated DNA

DNA

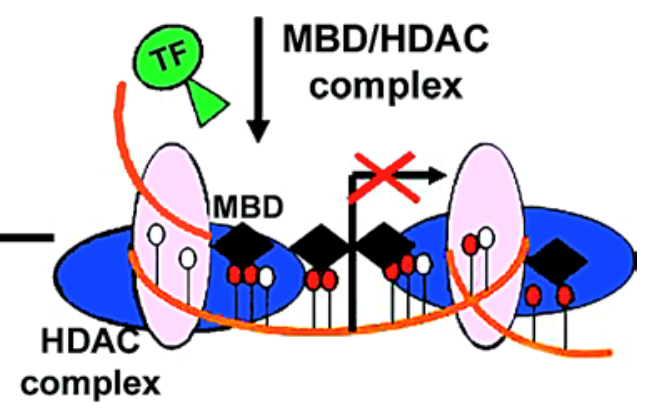

Histone deacetylation, Chrornation condensation

Figure 1 - Epigenetic silencing of gene expression. DNA methyl-transferases carry out the methylation of CpG dinucleotides, which triggers the process of gene silencing by recruitment of methyl binding domain (MBD) and Histone deacetylases $(H D A C)$ to bind to the methylated DNA. This results in histone deacetylation and chromatin condensation leading to loss of transcription factor binding and subsequent repression of transcription.

Epigenetic markers, particularly aberrant DNA methylation, have the potential as an useful diagnostic tumor marker. These markers can be detected in cancer tissues, serum and body fluids. The methylation markers have several advantages over the mutation based genetic markers. The detection of these markers is technically simple and can be sensitively detected both quantitatively and qualitatively by polymerase chain reaction (PCR). Furthermore, the incidences of aberrant DNA methylation are higher than those of mutations are and can be discovered by genome wide screening procedures (32).

In the recent years, the role of GSTP1 is being studied as a tumor marker widely. Gossel et al. reported that GSTP1 hypermethylation is seen in the serum of $72 \%$ patients with of Prostate cancer patients (33). They also examined the urine after prostatic massage and methylation was detected in $68 \%$ patients with early prostate cancer and $78 \%$ of patients with locally advanced cancer. Table- 2 shows methylation of GSTP1 in different tissue and body fluids. Harden et al. reported $73 \%$ GSTP1 methylation in prostate cancer tissue samples. They also reported that methylation assay with histological analysis improves the diagnostic specificity (34). Methylation of several other genes have been studied in the diagnosis of prostate cancer including, RARB, CD44, E- cadherin (ECAD), RASSF1A, APC and tazarotene induced gene 1 (T1G1) $(7,35)$. Recent 
Table 2 - GSTP1 methylation in prostate cancer $(8,33)$.

\begin{tabular}{lc}
\hline Specimen & Methylation $(\%)$ \\
\hline Tissue & 90 \\
Serum & 72 \\
Ejaculate & 50 \\
Urine after prostate massage & 76 \\
\hline
\end{tabular}

studies reported by Yegnasubramanian et al. (36) and others have reported that use of a panel of methylation markers including GSTP1 improves the diagnosis of prostate cancer both in body fluids and tissues. Further studies are needed before these markers can be used as diagnostic markers in the routine clinical practice.

\section{Prognostic Markers}

Kollerman et al. demonstrated that GSTP1 hypermethylation is seen in $40 \%$ of pre operative bone marrow aspirate in patients with advanced PC (37). They also found evidence of GSTP1 hypermethylation in $90 \%$ of PC patients with lymph node involvement where as in only $11 \%$ of lymph nodes in non cancer group. Genes such as CAV1, CDH1, CD 44 and T1G1 may exhibit specific methylation in high risk and Metastatic tumors that can be used in the molecular staging and predictors of disease progression (14). Prostate cancers with high Gleason score are correlated with a higher degree of methylation of many genes, such as RAR $\beta$, RASSF1A, GSTP1 and CDH13 (8). Further studies also indicate that use of panel of multiple methylation makers can be better predictors than individual genes (38).

\section{THERAPEUTIC TARGETS}

Epigenetic changes are heritable and potentially reversible. Hence, it is reasonable to expect that these can be used as potential therapeutic targets. Currently there are several drugs which are at different stages of development. They can be broadly classified in two groups: (i) DNMT inhibitors and (ii) Histone Deacetylase (HDAC) inhibitor. Some of the drugs in both groups, which are being tested and used currently, are shown in Table-3.

\section{DNMT Inhibitors}

5-aza-2' - Deoxycytidine (5-aza-dC) is one of the early drugs identified as DNMT inhibitor after being as cytotoxic drug around 1990. This drug forms irreversible covalent bonds with DNMT1 after its incorporation in to DNA, thereby inducing degradation of DNMT1 (39) Issa et al. (40) demonstrated that low dose continuous administration is more effective than higher doses. Myelosuppression is a known side effect of this drug which is otherwise well tolerated. 5-aza-dC has been recently approved by FDA for clinical use in certain hematological conditions. Another drug in the same group, Zebularine can be administered orally or intraperitoneally. It has to be given in high doses, however, it is chemically stable and has low toxicity (41). Other drugs in this which are being studied include Epigallocatechin-3 - Gallate (EGCG), Procainamide, Procaine and MG 98 (32).

\section{Histone Deacetylases (HDAC) Inhibitors}

A variety of natural products exhibit HDAC inhibitory activity. Commonly used HDAC inhibitors which are being tested include trichostatin A (TSA), Suberoylanilide hydroxamic acid (SAHA) and valproic acid (9). Many of these drugs have exhibited antitumor activity. SAHA and sodium butyrate have shown prostate cancer inhibition in animal models $(42,43)$. Overall, low toxicity rates of these drugs are encouraging in conducting further studies.

Table 3 - Drugs used for epigenetic modifications (9,32).

\begin{tabular}{ll}
\hline DNMT Inhibitors & \multicolumn{1}{c}{ HDAC Inhibitors } \\
\hline 5-aza-2'- Deoxycytidine & $\begin{array}{l}\text { Trichostatin A (TSA) } \\
\text { Zebularine }\end{array}$ \\
$\begin{array}{l}\text { Sodium butyrate } \\
\text { Procainamide } \\
\text { hydroylanilide } \\
\text { Procaine }\end{array}$ & Valproic acid \\
Epigallocate & \\
chin-3-gallate (EGCG) & Pyroxamide \\
MG98 & Phenyl butyrate \\
\hline
\end{tabular}


The combination of HDAC and DNMT inhibitors has synergistic effect in the reactivation of silenced gene (9). Another interesting possibility is the combination of epigenetic drugs and conventional anti androgens and chemotherapeutic agents. It should be cautioned that the epigenetic drugs currently lack gene specificity and some of them are associated with significant toxicity. Hence, efforts are being made to develop gene specific epigenetic drugs (32).

\section{SUMMARY AND FUTURE DIRECTIONS}

Epigenetic changes in prostate cancer are being studied extensively at present and genome wide screening will lead to development of novel epigenetic markers. Epigenetic changes are early event in cancer development and hence can be used to assess the risk of developing cancer. $\mathrm{Li}$ et al. suggest that genes such as CAV1, CDH1, CD44 and T1G1 should be explored further as "risk markers", particularly to differentiate the indolent tumors from others with bad prognostic potential (14). Epigenetic molecular classification will help to identify patients at high risk of recurrence following definitive treatments such as radical prostatectomy. Therapeutic drugs which reverse these epigenetic changes have the potential to be an effective adjunct treatment for prostate cancer. However, they need to be studied both for its efficacy and safety profile. Gene specific epigenetic drugs need to be developed for better targeting of the disease. As the epigenetic changes are early event in the PC development, these drugs have a potential to play a role in disease prevention. Two main features of epigenetic changes, "reversibility" and being an "early event" in tumorigenesis, makes epigenetic targeting as an important future research area for cancer diagnosis, risk stratification, treatment and prevention resulting in effective cancer control.

\section{CONFLICT OF INTEREST}

None declared.

\section{REFERENCES}

1. Jemal A, Murray T, Ward E, Samuels A, Tiwari RC, Ghafoor A, Feuer EJ, et al.: Cancer statistics, 2005. CA Cancer J Clin. 2005; 55: 10-30. Erratum in: CA Cancer J Clin. 2005; 55: 259.

2. Wolffe AP, Matzke MA: Epigenetics: regulation through repression. Science. 1999; 286: 481-6.

3. Crawford ED: Epidemiology of prostate cancer. Urology. 2003; 62: 3-12.

4. Smith RA, Cokkinides V, Eyre HJ: American Cancer Society guidelines for the early detection of cancer, 2003. CA Cancer J Clin. 2003; 53: 27-43.

5. Thompson IM, Pauler DK, Goodman PJ, Tangen CM, Lucia MS, Parnes HL, et al.: Prevalence of prostate cancer among men with a prostate-specific antigen level < or =4.0 ng per milliliter. N Engl J Med. 2004; 350: 2239-46. Erratum in: N Engl J Med. 2004; 351: 1470.

6. Stamey TA, Caldwell M, McNeal JE, Nolley R, Hemenez M, Downs J: The prostate specific antigen era in the United States is over for prostate cancer: what happened in the last 20 years? J Urol. 2004; 172: 1297-301.

7. Singal R, Ferdinand L, Reis IM, Schlesselman JJ: Methylation of multiple genes in prostate cancer and the relationship with clinicopathological features of disease. Oncol Rep. 2004; 12: 631-7.

8. Das PM, Singal R: DNA methylation and cancer. J Clin Oncol. 2004; 22: 4632-42.

9. Li LC, Carroll PR, Dahiya R: Epigenetic changes in prostate cancer: implication for diagnosis and treatment. J Natl Cancer Inst. 2005; 97: 103-15.

10. Egger G, Liang G, Aparicio A, Jones PA: Epigenetics in human disease and prospects for epigenetic therapy. Nature. 2004; 429: 457-63.

11. Rodenhiser D, Mann M: Epigenetics and human disease: translating basic biology into clinical applications. CMAJ. 2006; 174: 341-8.

12. Peterson CL, Laniel MA: Histones and histone modifications. Curr Biol. 2004; 14: R546-51.

13. Rountree MR, Bachman KE, Herman JG, Baylin SB: DNA methylation, chromatin inheritance, and cancer. Oncogene. 2001; 20: 3156-65.

14. Li LC, Okino ST, Dahiya R: DNA methylation in prostate cancer. Biochim Biophys Acta. 2004; 1704: 87-102.

15. Robertson KD: DNA methylation and chromatin unraveling the tangled web. Oncogene. 2002; 21: 536179. 
16. Nelson CP, Kidd LC, Sauvageot J, Isaacs WB, De Marzo AM, Groopman JD, et al.: Protection against 2-hydroxyamino-1-methyl-6-phenylimidazo[4,5b]pyridine cytotoxicity and DNA adduct formation in human prostate by glutathione S-transferase P1. Cancer Res. 2001; 61: 103-9.

17. Konishi N, Nakamura M, Kishi M, Nishimine M, Ishida E, Shimada K: DNA hypermethylation status of multiple genes in prostate adenocarcinomas. Jpn J Cancer Res. 2002; 93: 767-73.

18. Oh HJ, Lee KK, Song SJ, Jin MS, Song MS, Lee JH, et al.: Role of the tumor suppressor RASSF1A in Mst1mediated apoptosis. Cancer Res. 2006; 66: 2562-9.

19. Song MS, Song SJ, Ayad NG, Chang JS, Lee JH, Hong HK, et al.: The tumour suppressor RASSF1A regulates mitosis by inhibiting the APC-Cdc20 complex. Nat Cell Biol. 2004; 6: 129-37.

20. Sekita N, Suzuki H, Ichikawa T, Kito H, Akakura K, Igarashi T, et al.: Epigenetic regulation of the KAI1 metastasis suppressor gene in human prostate cancer cell lines. Jpn J Cancer Res. 2001; 92: 947-51.

21. Schmitt JF, Millar DS, Pedersen JS, Clark SL, Venter DJ, Frydenberg M, et al.: Hypermethylation of the inhibin alpha-subunit gene in prostate carcinoma. Mol Endocrinol. 2002; 16: 213-20.

22. Chen H, Toyooka S, Gazdar AF, Hsieh JT: Epigenetic regulation of a novel tumor suppressor gene (hDAB2IP) in prostate cancer cell lines. J Biol Chem. 2003; 278: 3121-30.

23. Bedford MT, van Helden PD: Hypomethylation of DNA in pathological conditions of the human prostate. Cancer Res. 1987; 47: 5274-6.

24. Bhattacharya SK, Ramchandani S, Cervoni N, Szyf M: A mammalian protein with specific demethylase activity for mCpG DNA. Nature. 1999; 397: 579-83.

25. Luger K, Mader AW, Richmond RK, Sargent DF, Richmond TJ: Crystal structure of the nucleosome core particle at 2.8 A resolution. Nature. 1997; 389: 25160.

26. Jenuwein T, Allis CD: Translating the histone code. Science. 2001; 293: 1074-80.

27. Huang H, Reed CP, Zhang JS, Shridhar V, Wang L, Smith DI: Carboxypeptidase A3 (CPA3): a novel gene highly induced by histone deacetylase inhibitors during differentiation of prostate epithelial cancer cells. Cancer Res. 1999; 59: 2981-8.

28. Tsubaki J, Hwa V, Twigg SM, Rosenfeld RG: Differential activation of the IGF binding protein-3 promoter by butyrate in prostate cancer cells. Endocrinology. 2002; 143: 1778-88.
29. Rauen KA, Sudilovsky D, Le JL, Chew KL, Hann B, Weinberg V, et al.: Expression of the coxsackie adenovirus receptor in normal prostate and in primary and metastatic prostate carcinoma: potential relevance to gene therapy. Cancer Res. 2002; 62: 3812-8.

30. Moggs JG, Goodman JI, Trosko JE, Roberts RA: Epigenetics and cancer: implications for drug discovery and safety assessment. Toxicol Appl Pharmacol. 2004; 196: 422-30.

31. Nakayama T, Watanabe M, Yamanaka M, Hirokawa Y, Suzuki H, Ito $\mathrm{H}$, et al.: The role of epigenetic modifications in retinoic acid receptor beta2 gene expression in human prostate cancers. Lab Invest. 2001; 81: 1049-57.

32. Miyamoto K, Ushijima T: Diagnostic and therapeutic applications of epigenetics. Jpn J Clin Oncol. 2005; 35: 293-301.

33. Goessl C, Krause H, Muller M, Heicappell R, Schrader M, Sachsinger J, et al.: Fluorescent methylationspecific polymerase chain reaction for DNA-based detection of prostate cancer in bodily fluids. Cancer Res. 2000; 60: 5941-5.

34. Harden SV, Guo Z, Epstein JI, Sidransky D: Quantitative GSTP1 methylation clearly distinguishes benign prostatic tissue and limited prostate adenocarcinoma. J Urol. 2003; 169: 1138-42.

35. Tokumaru Y, Harden SV, Sun DI, Yamashita K, Epstein JI, Sidransky D: Optimal use of a panel of methylation markers with GSTP1 hypermethylation in the diagnosis of prostate adenocarcinoma. Clin Cancer Res. 2004; 10: 5518-22.

36. Yegnasubramanian S, Kowalski J, Gonzalgo ML, Zahurak M, Piantadosi S, Walsh PC, et al.: Hypermethylation of $\mathrm{CpG}$ islands in primary and metastatic human prostate cancer. Cancer Res. 2004; 64: 1975-86.

37. Kollermann J, Muller M, Goessl C, Krause H, Helpap B, Pantel K, et al.: Methylation-specific PCR for DNAbased detection of occult tumor cells in lymph nodes of prostate cancer patients. Eur Urol. 2003; 44: 533-8.

38. Rhodes DR, Sanda MG, Otte AP, Chinnaiyan AM, Rubin MA: Multiplex biomarker approach for determining risk of prostate-specific antigen-defined recurrence of prostate cancer. J Natl Cancer Inst. 2003; 95: 661-8.

39. Christman JK: 5-Azacytidine and 5-aza-2'deoxycytidine as inhibitors of DNA methylation: mechanistic studies and their implications for cancer therapy. Oncogene. 2002; 21: 5483-95.

40. Issa JP, Garcia-Manero G, Giles FJ, Mannari R, 
Thomas D, Faderl S, et al.: Phase 1 study of low-dose prolonged exposure schedules of the hypomethylating agent 5-aza-2'-deoxycytidine (decitabine) in hematopoietic malignancies. Blood. 2004; 103: 163540.

41. Cheng JC, Weisenberger DJ, Gonzales FA, Liang G, $\mathrm{Xu}$ GL, Hu YG, et al.: Continuous zebularine treatment effectively sustains demethylation in human bladder cancer cells. Mol Cell Biol. 2004; 24: 1270-8.
42. Butler LM, Agus DB, Scher HI, Higgins B, Rose A, Cordon-Cardo C, et al.: Suberoylanilide hydroxamic acid, an inhibitor of histone deacetylase, suppresses the growth of prostate cancer cells in vitro and in vivo. Cancer Res. 2000; 60: 5165-70.

43. Kuefer R, Hofer MD, Altug V, Zorn C, Genze F, KunziRapp K, et al.: Sodium butyrate and tributyrin induce in vivo growth inhibition and apoptosis in human prostate cancer. Br J Cancer. 2004; 90: 535-41.

Correspondence address:

Dr. Murugesan Manoharan

Associate Professor of Urology

University of Miami School of Medicine

P.O. Box 016960 (M814)

Miami, Florida, 33101, USA

Fax: + 1305 243-4653

E-mail:mmanoharan@med.miami.edu 